tác dụng phụ trên tim mạch $8 \%$ và tiêu hóa $4 \%$. Điều này cũng phù hợp với các tài liệu trong y văn chỉ ra những thay đổi dược động học của thuốc ở người già đặc biệt với nhóm thuốc hướng thần trong đó có nhóm an thần kinh, chống trầm cảm tác động không chọn lọc trên serotonin dễ tăng nguy cơ tác dụng phụ kháng cholinergic․ Do đó khi lựa chọn thuốc hướng thần trên đối tượng người già cần cân nhắc, thân trọng và theo dõi phát hiện sớm các tác dụng không mong muốn.

\section{KẾT LUÂN}

Các triêu chứng đau cải thiên rõ rêt về số lượng vị trí và mức độ đau cùng với sự cải thiện trầm cảm khi được điều trị liệu pháp hóa dược phối hợp CTC, ATK yên dịu liều thấp, bình thần có thể dùng ngắn ngày. Chưa thấy sự khác biệt thuyên giảm đau giữa các mức độ trầm cảm. Tác dụng không mong muốn kháng cholinergic hay gặp ở nhóm bệnh nhân trầm cảm người già hơn so với các tác dụng không mong muốn khác.

TÀI LIỆU THAM KHẢO
1. Zivin $K$, Wharton $T$, Rostant $O$ (2013). The Economic, Public Health, and Caregiver Burden of Late-life Depression. Psychiatric Clinics of North America, 36(4), 631-649.

2. Fiske A, Wetherell JL, Gatz M (2009). Depression in Older Adults. Annu Rev Clin Psychol, 5(1), 363-389.

3. Silva MR da, Ferretti F, Pinto $S$ da $S$ et al (2018). Depressive symptoms in the elderly and its relationship with chronic pain, chronic diseases, sleep quality and physical activity level. Brazilian Journal Of Pain, 1(4).

4. Zis P, Daskalaki A, Bountouni I, et al (2017). Depression and chronic pain in the elderly: links and management challenges. Clin Interv Aging, 12:709-720.

5. Raskin J, Wiltse CG, Siegal A, et al (2007) Efficacy of duloxetine on cognition, depression, and pain in elderly patients with major depressive disorder: an 8-week, double-blind, placebocontrolled trial. Am J Psychiatry, 164(6).

6. Demyttenaere $K$, Reed C, Quail $D$, et al (1981). Presence and predictors of pain in depression: Results from the FINDER study. Journal of Affective Disorders, 125(1-3):53-60.

7. Boss GR, Seegmiller JE(2021). Age-Related Physiological Changes and Their Clinical Significance. West J Med. 135(6):434-440.

\title{
KẾT QUẢ PHẪU THUÂTT KHÂU BÍT TÚI SA TRỰC TRÀNG CẢI TIẾN ĐIỀU TRI HộI CHỨNG TẮC NGHẼ̃N ĐƯỜNG RA DO SA TRỰC TRÀNG KIỂU TÚI TẠI BỆNH VIÊ̂N ĐẠI HỌC HÀ NộI
}

\author{
Nguyễn Thị Thu Vinh*, Nguyễn Xuân Hùng**, Trần Ngọc Dũng*,
} Lưu Quang Dũng*, Hoàng Đình Âu*

\section{TÓM TẮT}

Đặt vấn đề: Hội chứng tức nghẽn đường ra (Osbtructed defecation syndrome-ODS) có nguyên nhân là những tổn thương cơ học tại vùng hậu môn trực tràng; trong đó sa trực tràng kiểu túi (Rectocel) là nguyên nhân thường găp. Để xác định thương tổn này cần phải có phương tiện chẩn đoán hình ảnh là chụp công hưởng từ động hoc tống phân (MRI Defecography). Về điêu trị, cần đánh giá kết quả điễu tri bằng phẫu thuât. Muc tiêu: Đánh giá kết quả phẫu thuật khâu bít túi sa trực tràng cải tiến điều trị hội chứng tắc nghiẽn đường ra do sa trực tràng kiếu túi tại bệnh viện Đại học Y Hà Nội. Đối tượng và phướng pháp nghiên cứu: Bệnh nhân có hội chứng tắc nghẽn đường ra do sa trực tràng kiểu túi theo thang điểm Rome IV (2016) và thang điểm 5 tiêu chí

*Bênh viện Đại học Y Hà Nội

**Bênh viên Viêt Đức

Chịu trách nhiệm chính: Nguyễn Thị Thu Vinh

Email: nguyenthuvinh86@gmail.com

Ngày nhận bài: 25.6.2021

Ngày phản biên khoa hoc: 20.8.2021

Ngày duyệt bài: 27.8.2021 của Adofo Renzi (2012); có kèm/ không kèm sa niêm trong trực tràng trên MRI defecography. Đánh giá kết quả điêu trị dựa trên sự cải thiện của triệu chứng theo Rome IV và thang điểm 5 tiêu chí của Adolfo Renzi. Phương pháp nghiên cứu mô tả loat bênh. Kết quả: Từ 01/2018 đến 12/2020, $30 \mathrm{ca}$ được chẩn đoán và phẫu thuật khâu treo cải tiến tai Bênh viện Đai học Y. Kết quả sau mổ rất tốt và tốt $80 \%$, cải thiện $100 \%$ triệu chứng đại tiện khó phải rặn. Biến chứng sau mổ có $5 / 30(16,7 \%)$ bệnh nhân bí tiểu sau mổ. Kết luận: Chup cộng hưởng từ động học tống phân là phưởng pháp chẩn đoán chính xác thương tôn sa trực tràng kiểu túi. Phẩu thuâat khâu bít túi sa trực tràng cải tiến cho kết quả tốt, ít biến chứng.

Tư khóa: Hội chứng đại tiện tắc nghẽn; Túi sa trực tràng; Sa niêm trong trực tràng; Phẫu thuật STARR; Phẫu thuật khâu treo NTV.

\section{SUMMARY \\ THE RESULTS OF SURGICAL TO TREAT THE OBSTRUCTED DEFECATION SYNDROME CAUSED BY RECTOCELE AT HANOI MEDICAL UNIVERSITY HOSPITAL \\ Introduction: Evaluate the diagnosis and}


treatment outcomes for constipations due to Obstructed defecation syndrome (ODS). Rectocele is hernia of the anterior rectal wall into the vagina. Defecography is the Xray method to evaluate this defect. Purpoes: Describing results of surgical to treat the obstructed defecation syndrome (ODS) caused by rectocele at Hanoi Medical University Hospital. Methods: Female patients: Obstructed defecation syndrome standard by Rome IV criteria and Adolfo Renzi. Rectocele and/ or not mucosal prolapse syndrome (MRI defecography). Results of Surgery: Assessing functions of defecation by Rome IV criteria (2016), Five-Item Score for ODS by Adolfo Renzi (2012). Results: For 2 years, there were 30 patients who had rectocele were evaluated by defecography and surgical repaired $80 \%$ excellent result, $100 \%$ improve the symptoms difficult to defecate. 5 patient $(16,7 \%)$ who had urinary retention. Conclusion: Surgical repair of rectocele improve the difficult evacuation, good result and less complications

Keywords: Obstructed defecation syndrome, Rectocele, Internal rectal prolapse, STARR procedure, Circular lifting suture (NTV's procedure).

\section{I. ĐẶT VẤN ĐỀ}

Hội chứng tắc nghẽn đường ra (ODS) có nguyền nhân là những tổn thương cơ học tại vùng hậu môn trực tràng; trong đó sa trực tràng kiểu túi là nguyển nhân thường gặp [7]. Phần lớn bệnh nhân đến khám thường không triệu chứng hoặc chỉ đại tiện khó gây ảnh hưởng đời sống sinh hoạt, thường kèm sa các tạng chậu, dễ chẩn đoán nhầm hoặc không đây đủ nếu chỉ dựa vào khám lâm sàng. Chụp cộng hưởng từ động học tống phân giúp chẩn đoán rõ thương tổn sa trực tràng kiểu túi kèm tổn thương phối hợp như sa niêm trong, lồng trực tràng - trực tràng [3]. Có nhiều phương pháp điều trị sa trực tràng kiểu túi có tỷ lệ khỏi bệnh và tái phát khác nhau [2].

Mục tiêu nghiên cứu: Đánh giá kêt quả phẫu thuật khâu bít túi sa trực tràng cải tiến điều trị hội chứng tắc nghiẽn đường ra do sa trực tràng kiểu túi tại bệnh viện Đại học Y Hà Nội.

\section{II. ĐỐI TƯỢNG VÀ PHƯƠNG PHÁP NGHIÊN CỨU}

- Đối tượng nghiên cứu: Bệnh nhân có hội chứng tắc nghẽn đường ra do sa trực tràng kiểu túi được phẫu thuật tại Khoa Ngoại tổng hợp Bệnh viện Đại học Y.

- Thiết kế nghiên cứu: nghiên cứu mô tả loạt bệnh. Tiêu chuẩn chọn bệnh nhân có hội chứng tắc nghẽn đường ra do sa trực tràng kiểu túi theo tiêu chuẩn Rome IV (2016) và thang điểm 5 tiêu chí của Adolfo Renzi (2012); kích thước túi sa vừa $(R \leq 4 \mathrm{~cm})$, có kèm/ không kèm sa niêm trong trực tràng trên MRI Defecography. Đánh giá kết quả phẫu thuật dựa trên sự cải thiện triệu chứng theo tiêu chuẩn Rome IV[6] và thang điểm 5 tiêu chí của Adolfo Renzi[4].

Bảng 1: Thang điểm đánh giá hội chứng đại tiện tắc nghẽn 5 tiêu chí của Adolfo Renzi

\begin{tabular}{|c|c|}
\hline Triệu chứng & \\
\hline iều & \\
\hline hông hoàn toàn & \\
\hline Dùng $t$ & \\
\hline Dùng & \\
\hline Khó chịu/đau bụng & \\
\hline \multicolumn{2}{|c|}{$\begin{array}{l}\text { Bảng 2: Tiêu chuẩn chẩn đoán Rome IV } \\
\text { cho táo bón [6] }\end{array}$} \\
\hline \multicolumn{2}{|c|}{ 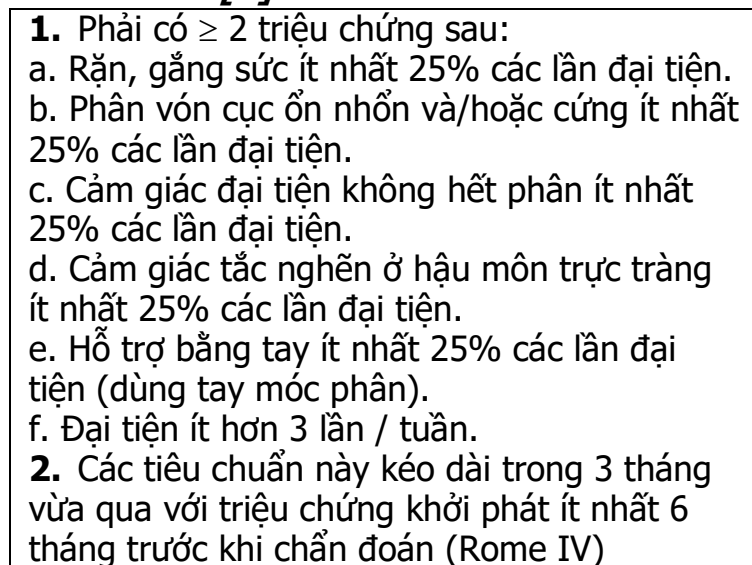 } \\
\hline
\end{tabular}

- Quy trình nghiên cứu 
Bước 1: Xác định đỉnh túi rectocele (Hình 2)

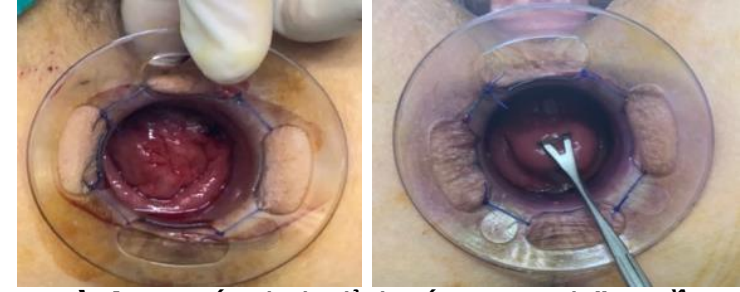

Hình 2: Xác định đỉnh túi rectocele"Nguồn:

Bênh viên Đại hoc $Y-B N$ Nguyễn Thị $X .60 T^{\prime \prime}$

Bước 2: Khâu bít toàn thành thành trước trực tràng (Hình $3 \mathrm{~A}$.)

Bước 3: Khâu gấp niêm mạc thành sau trực tràng (Hình 3B).

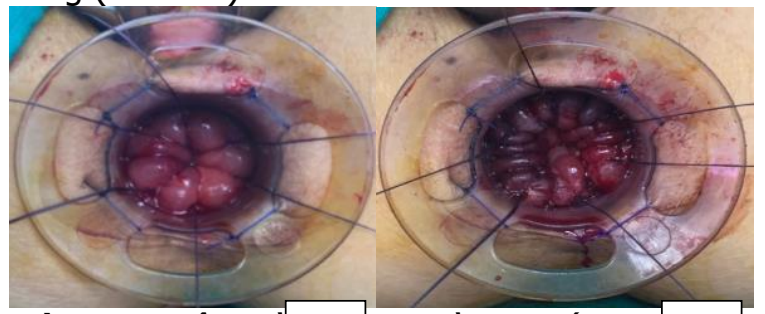

Hình 3: Khâu toà A hh thành trước trực B và khâu gấp nếp rmcrm mạc thành sau trực cramg. "Nguồn: Bệnh viện Đại học Y, BN Nguyễn Thị X. 60T"
- Đánh giá kết quả điêu trị

+ Giảm bệnh: tổng số điểm theo Adolfo từ 7 9 điểm. MRI Defecpgraphy còn STTKT độ I theo Yang. Không giảm bệnh khi không đạt tiêu chuẩn trên.

+ Khỏi bệnh: tổng số điểm theo Adolfo $<7$ điểm. MRI Defecpgraphy giảm kích thước độ sâu của túi sa về giới hạn gần bình thường. Không khỏi bênh khi không đạt tiêu chuẩn trên.

- Đánh giá kết quả điều trị rất tốt, tốt, trung bình, kén dựa trên cải thiện triệu chứng theo tiêu chuẩn Rome IV

\section{KẾT QUẢ NGHIÊN CỨU}

Trong thời gian từ tháng $1 / 2018$ đến tháng 12/2020, chúng tôi tiến hành phẫu thuật $30 \mathrm{ca}$ đại tiện tắc nghẽn do sa trực tràng kiểu túi, kết quả như sau: Triệu chứng thường găp là đại tiện khó phải rặn, đại tiện không hết phân. Khám lâm sàng thấy đa số STTKT mức DeLancey II 28 (93,3\%), 100\% độ II theo Yang (độ sâu túi sa thấp nhất là $2,1 \mathrm{~cm}$; cao nhất là $4 \mathrm{~cm}$ ). Thời gian phâuu thuật và hậu phẫu ngắn, ít đau sau mổ. Chỉ có biến chứng bí tiểu sau mổ 5/ 30 (16,7\%) bệnh nhân.

Bảng 3: Cải thiện triệu chứng táo bón theo tiêu chuẩn Rome IV

\begin{tabular}{|c|c|c|c|}
\hline Tiêu chuẩn rome iv & Trước mố & Cải thiện sau mố & Tỷ lệ \\
\hline Rặn nhiều khi đai tiện* & 30 & 30 & $100 \%$ \\
\hline Phân cứng/ Phân cục* & 30 & 28 & $93,3 \%$ \\
\hline Đại tiện không hết phân* & 30 & 27 & $90 \%$ \\
\hline Tắc nghẽn ở hậu môn trực tràng* & 19 & 16 & $84,2 \%$ \\
\hline Hố trợ đại tiện bằng tay / thụt tháo* & 25 & 24 & $96 \%$ \\
\hline Đại tiệ̂n <3 lần/ tuầ* & 5 & 5 & $100 \%$ \\
\hline
\end{tabular}

$* \geq 25 \%$ số lần đại tiên

Nhận xét: Sau mổ cải thiện hoàn toàn triệu chứng phải rặn nhiều khi đại tiện. Kết quả sau mổ rất tốt và tốt là $24 / 30(80 \%)$.

Bảng 4: Cải thiện phân bố các nhóm bệnh theo thang điểm 5 tiêu chí của Adolfo

\begin{tabular}{|c|c|c|c|c|c|c|}
\hline \multirow{2}{*}{$\begin{array}{l}\text { Điểm } 5 \text { tiêu chí } \\
\text { theo Adolfo }\end{array}$} & \multicolumn{2}{|c|}{ Nhóm $<7$ điểm } & \multicolumn{2}{|c|}{ Nhóm 7 - 9 điểm } & \multicolumn{2}{|c|}{ Nhóm > 9 điểm } \\
\hline & Số BN & Tỷ lệ \% & Số BN & Tỷ lệ \% & Số BN & Tỷ lệ \% \\
\hline Trước mố & 0 & 0 & 0 & 0 & 30 & 100 \\
\hline Sau mố 1 tháng & 29 & 96,7 & 1 & 3,3 & 0 & 0 \\
\hline Sau mố 3 tháng & 27 & 90 & 3 & 10 & 0 & 0 \\
\hline Sau mố 6 tháng & 24 & 80 & 4 & 13,3 & 2 & 6,7 \\
\hline
\end{tabular}

Nhận xét: Trước mổ: $100 \%$ bệnh nhân thuộc nhóm > 9 điểm. Sau mổ 1 tháng: Nhóm có điểm < 7 điểm (khỏi bệnh) chiếm 96,7\%. Nhóm từ $7-9$ điểm (giảm bệnh) chiếm 3,3\%. Nhóm trên 9 điểm $0 \%$. Tuy nhiên tỷ lệ khỏi bênh giảm dân sau 3 tháng, 6 tháng, tỷ lệ giảm bệnh tăng dần sau 3 tháng, 6 tháng. Chúng tôi chỉ định chụp lại MRI Defecography sau mố 1 tháng được $16 / 30 \mathrm{ca}$, trong đó có $14 / 16(87,5 \%)$ ca khổng còn túi sa thành trước trực tràng, 2/16 $(12,5 \%)$ ca có túi sa độ I theo Yang.

\section{BÀN LUÂ̂N}

Theo Anthony Lembo (2003) [7] hội chứng tắc nghẽn đường ra gồm 2 loại: (1) Tắc nghẽn đường ra vật lý: bất đồng vận cơ sàn chậu (Anismus), phì đại cơ thắt trong hậu mổn (Achalasia), phình giãn đại tràng bẩm sinh hoă̆c mắc phải... (2) Tắc nghẽn đường ra giải phẫu: sa trực tràng kiểu túi (STTKT - Rectocele), các túi sa vùng đỉnh gồm sa tử cung, sa ruột non (enterocele)/đại tràng sigma (sigmoidocele)/mõ 
mạc nối (peritoneocele), sa trong (lồng) trực tràng hậu môn (rectoanal intussusceptions) và sa ngoài trực tràng (rectal prolapse). Trong đó STTKT là thường gặp nhất, có thể do bẩm sinh hoặc mắc phải. Ở nữ trưởng thành, tỷ lệ khám thẩy STTKT khoảng $20-80 \%$ và thường không triệu chứng trừ khi kích thước lớn $(R>3 \mathrm{~cm})$ và/hoặc đi kèm với sa trong trực tràng. Chụp cộng hưởng từ động học tống phân giúp chẩn đoán rõ thương tổn STTKT kèm tổn thương phối hợp như sa niêm trong, lồng trực tràng - trực tràng.

Trong nghiên cứu của chúng tôi, triệu chứng đại tiện khó phải rặn nhiều, phân vón cục lổn nhổn và/hoặc cứng, cảm giác đại tiện không hết phân có trền tất cả các trường hợp $(100 \%)$, 25/30 (83,3\%) trường hợp phải dùng tay để hổ trợ đại tiện. Các triệu chứng này đều cao hơn kết quả nghiên cứu của Nguyễn Đình Hối và cS (2005) [1]: rặn nhiều khi đại tiện (93\%), cảm giác đại tiện không hết phân (94\%).

Trong số 30 ca phẫu thuật thì 100\% các bệnh nhân có mức độ túi sa độ II theo Yang. Kích thước túi sa trực tràng trước mổ trung bình là $3,34 \pm 0,53 \mathrm{~cm}$, kích thước túi sa lớn nhất là 4 cm. Theo Renzi A. và cộng sự (2008) [5] kích thước túi sa thành trước trực tràng trước mổ trung bình là $3,4 \pm 1,5 \mathrm{~cm}$.

Sau mổ sự cải thiện 3 triệu chứng theo Rome IV: rặn nhiều, phân cứng, đại tiện không hết phân thường gặp nhất trong hội chứng đại tiện tắc nghẽn $100 \%$. Kết quả sau mổ rất tốt và tốt là 24/30 (80\%). Theo Nguyễn Đình Hối [1], tỷ lệ cải thiện triệu chứng theo Rome IV là $79,1 \%$.

Trước mổ, điểm Adolfo trung bình là 15,93; thấp nhất là 11 điểm, cao nhất là 19 điểm. Sau mổ 6 tháng điểm 5 tiêu chí trung bình là 4,06 điểm; thấp nhất 1 điểm, cao nhất 10 điểm.Có $2 / 30(6,7 \%)$ trường hợp kết quả sau mổ kém dần tiếp tục tập vật lý sàn chậu và theo dõi tiếp kết quả dài hạn.

\section{KẾT LUÂ̂N}

- Với những bệnh nhân táo bón trên 1 năm và có triệu chứng của hội chứng đại tiện tắc nghẽn cần chụp cộng hưởng từ động học tống phân để tìm nguyên nhân.

- Phẫu thuâat khâu bít túi sa trực tràng cải tiến cho kết quả tốt, an toàn, hiệu quả, ít biến chứng.

\section{TÀI LIỆ THAM KHẢO}

1. Nguyễn Đình Hối, Dương Phước Hưng, Nguyến Văn Hậu và cộng sự (2005). Đánh giá kết quả phẫu thuật điều trị chứng táo bón do sa trực tràng kiểu túi. Tạp Chí Học TP Hồ Chí Minh, 9, $10-16$.

2. Nguyê̂̀n Trung Vinh (2015), Sàn chậu học, Nhà xuất bản $Y$ học.

3. López A., Żetterström J., và Mellgren A.F. (2005). Defecography: A Swedish Perspective. Complex Anorectal Disorders: Investigation and Management. Springer, London, 199-216.

4. Renzi A., Brillantino A., Di Sarno G. và công sự. (2013). Five-Item Score for Obstructed Defecation Syndrome: Study of Validation. Surg Innov, 20(2), 119-125.

5. Renzi $A_{\text {., }}$ Talento $P_{\text {., }}$ Giardiello $C$. và cộng sự. (2008). Stapled trans-anal rectal resection (STARR) by a new dedicated device for the surgical treatment of obstructed defaecation syndrome caused by rectal intussusception and rectocele: early results of a multicenter prospective study. Int J Colorectal Dis, 23(10), 999-1005.

6. Simren M., Palsson O.S., và Whitehead W.E. (2017). Update on Rome IV Criteria for Colorectal Disorders: Implications for Clinical Practice. Curr Gastroenterol Rep, 19(4), 15.

7. Lembo A.và Camilleri M. (2003). Chronic Constipation. NEngl J Med, 349(14), 1360-1368.

\section{MÔ HÌNH TÂTT KHÚC XẠ Ở TRẺ 6 TUỔI TẠI BÊ̂NH VIÊ̂N MẮT TRUNG ƯO'NG}

\section{TÓM TẮT}

Mục tiêu: Đánh giá mô hình tật khúc xạ ở trẻ 6 tuổi tại Bệnh viện Mắt Trung Ương và một số yếu tố

\footnotetext{
${ }^{1}$ Bệnh viện Mắt Sài Gòn Vinh

${ }^{2}$ Bệnh viện Mắt Trung Ương

Chịu trách nhiệm chính: Nguyễn Thị Nga

Email: Drnganguyen37@gmail.com

Ngày nhận bài: 22.6.2021

Ngày phản biên khoa học: 18.8.2021

Ngày duyệt băi: 25.8.2021
}

\section{Nguyễn Thị Nga ${ }^{1}$, Nguyễn Thị Thu Hiền ${ }^{2}$}

liên quan. Đối tượng và phương pháp nghiên cứu: nghiên cứu mô tả cắt ngang, thực hiện trên 117 trẻ 6 tuổi với 228 mắt được chẩn đoán tật khúc xạ tại khoa Khúc xa Bệnh Viện Mắt Trung Ương từ tháng $9 / 2020$ đến 7/2021. Kết quả: Hình thái tật khúc xạ phô̂̉ biến nhất là loan thị $(74,1 \%)$, tiếp theo đó là viễn thị $(19,3 \%)$ và cận thị $(6,6 \%)$. Mức độ tật khúc xạ cao trong nghiên cứu của chúng tôi có xu hướng cao hơn các nghiên cứu trong cộng đồng. Nhược thị chiếm tỷ lệ cao $42,1 \%$ trẻ mắc tật khúc xạ. Khônng có mối liên quan giữa tật khúc xa và giới tính $(p>0,05)$. Hình thái tật khúc xạ có mối liên quan tới mức độ nhược thị. 